\title{
A Rare Case Series of Cerebral Venous Thrombosis and Stroke in Young Male COVID-19 Positive Patients without Significant Comorbidities and Importance of Various Laboratory Investigations
}

\author{
Hardik Lalit Siroya, Bhagavatula Indira Devi*, Sachin Jose Pulickal, Dhanjaya Ishwar Bhat \\ Department of Neurosurgery, National Institute of Mental Health and Neuro Sciences (NIMHANS), Bengaluru, Karnataka, India \\ Email: *siroyahardik@hotmail.com
}

How to cite this paper: Siroya, H.L., Devi, B.I., Pulickal, S.J. and Bhat, D.I. (2022) A Rare Case Series of Cerebral Venous Thrombosis and Stroke in Young Male COVID19 Positive Patients without Significant Comorbidities and Importance of Various Laboratory Investigations. Open Access Library Journal, 9: e8343.

https://doi.org/10.4236/oalib.1108343

Received: December 30, 2021

Accepted: January 23, 2022

Published: January 26, 2022

Copyright $\odot 2022$ by author(s) and Open Access Library Inc.

This work is licensed under the Creative Commons Attribution International License (CC BY 4.0).

http://creativecommons.org/licenses/by/4.0/

\begin{abstract}
Background: Pandemic COVID-19 has irreversibly affected all nations worldwide leading to crisis in Global healthcare of unprecedented proportions. Here we present seven cases of CVT in COVID-19 patients with three rare cases one having cerebellar CVT and the other having deep seated basal ganglia bleed, one patient with CVT with known history of ALL. We evaluated 98 cases with covid positive status presenting to our institute with neurological symptoms. All patients underwent brain and chest CT imaging. Methods: It is an observational retrospective study conducted in pre-vaccination era. All covid positive cases who were operated in NIMHANS for Cerebral venous thrombosis are included. These surgeries are typically emergency surgeries. A proper consent was taken prior to surgery. Study period-march 2020 to December 2020 before vaccination drive started in India. Place of studyNational institute of mental health and neurosciences, NIMHANS, Bengaluru. Results and Interpretation: Also among the 7 cases presented 6 of them are young males. 5 did not have any prior known comorbidity. Not only the young females are being less operated, but also the young males are presenting more and most of them requiring surgical treatment. Conclusions: This neurotropism for young healthy males is far from understood. The eosinophil in peripheral blood was also extremely low in all the patients. Our data suggests that low eosinophil count though points towards severity in cerebral and pulmonary COVID-19, its non-improvement in these primary cases may suggest continued poor prognosis. Whether low eosinophil count portends to poor prognosis or severe COVID-19 leads to low eosinophil count is unclear and difficult to tell.
\end{abstract}




\section{Subject Areas}

Surgery \& Surgical Specialties

\section{Keywords}

Cerebral Venous Thrombosis, COVID-19, Eosinophil Count, Intracranial Haemorrhage, Stroke, Young Males

\section{Introduction}

Pandemic COVID-19 has irreversibly affected all nations worldwide leading to crisis in Global healthcare of unprecedented proportions. It was first reported as an outbreak of unknown respiratory illness leading to deaths on December 12, 2019. A novel strain on corona which had $79.5 \%$ genomic sequence homogeneity to severe acute respiratory syndrome coronavirus (SARS-CoV) [1], and the $50 \%$ homogeneity to Middle East respiratory syndrome coronavirus (MERS$\mathrm{CoV}$ ) [2] was isolated. Most cases of coronavirus infections are mild. SARS-CoV and MERS-CoV have mortality rates around $9.6 \%$ and $34 \%$, respectively. This severe acute respiratory syndrome coronavirus 2 (SARS-CoV2) causing coronavirus infectious disease 2019 (COVID-19) is a beta coronavirus causing over 198,234,951 cases and 4,227,359 deaths (5\%) till $2^{\text {nd }}$ August, 2021 as per WHO data base. India has been among the worst affected country after USA having $31,695,958$ cases and $424,773(1.3 \%)$ deaths till this date. Mortality rates in some countries are higher like Peru (9.3\%), Mexico (8.4\%), Ecuador (6.5\%) followed by Tunisia, Myanmar and South Africa. Although fever, cough, sore throat, shortness of breath, diarrhoea, myalgias are among the common symptoms, neurological symptoms like headache (11\%), hyposmia, dysgeusia, acute confusion, altered level of consciousness (9\%) and dizziness (8\%) have also been documented in almost $84 \%$. The receptor-binding domain in the S1 subunit [3] and amino acid sequences of the seven conserved replicase domains of Open Reading Frame 1ab (ORF1ab) bear extreme similarity to SARS-CoV-2; almost being $94 \%$ in the latter case [4]. Both SARS-CoV-2 and SARS-CoV hence share common binding properties to the angiotensin-converting enzyme 2 (ACE2) receptor on epithelial (especially respiratory) and endothelial human cells [3] [5] [6]. The potential neurotropic involvement of SARS-Cov-2 may thus be largely due to these receptors which are abundantly expressed in glial cells, neurons, endothelial and arterial smooth muscle cells in the brain [3] [5].

SARS-CoV has been isolated abundantly in the cerebrospinal fluid [7]. Apart from respiratory manifestations; neurological sequelae like ischemic and haemorrhagic strokes [8] [9], Cerebral venous thrombosis (CVT) [10] [11] [12], Encephalitis, acute disseminated encephalomyelitis (ADEM), Guillain-Barre syndrome (GBS), leukoencephalopathy, critical illness neuromyopathy [13] [14] secondary to SIRS (systemic inflammatory response syndrome), DIC (disseminated 
intravascular coagulation) and hypercoagulable stated have been documented [12] [15] [16]. Currently the data regarding COVID-19 and its neurological manifestations are just evolving. This study attempts to contribute and add information in the ever-increasing realm by specific cases of CVT along with peculiar patient characteristics in times of this dreadful disease seen in a busy specialised neurosurgical setup.

\section{Methods}

It is an observational retrospective study conducted in pre-vaccination era. All covid positive cases who were operated in NIMHANS for Cerebral venous thrombosis are included. These surgeries are typically emergency surgeries. A proper consent was taken prior to surgery.

Study period-March 2020 to December 2020 before vaccination drive started in India.

Place of study-National institute of mental health and neurosciences, NIMHANS, Bengaluru.

\section{Results}

Here we present seven cases of CVT and stroke with three atypical cases one having cerebellar CVT and the other having basal ganglia bleed, one patient with CVT with known history of ALL (Table 1) (Table 2). We evaluated 98 cases with covid positive status presenting to our institute with neurological symptoms. All patients underwent brain and chest CT (computed tomography) imaging.

Case $1 \rightarrow$ (Figure 1) (Table 1) (Table 2)-Represents the scan of case 1 of age 22 years. It shows CVT in the Left temporo-parietal region. Post-operative scan after 48 hours showed complete reversal of midline shift. Patient still remains to be in M5 sensorium even though the progressive chest $\mathrm{x}$-rays shows improvement. X rays show apical peripheral ground glass opacities. His eosinophil count did not increase with improvement in his chest status as may be expected in case of primary pulmonary cases suggesting a different characterisation in the way in which COVID-19 affects brain pointing towards a more localised pathology also playing a role along with systemic SIRS. LDH though elevated did not show significant improvement in following days which may again favour a localised pathology as chest imaging improved and so did his fever.

Case $2 \rightarrow$ (Figure 2) (Table 1) (Table 2)-shows a middle aged young male of age 38 years with bilateral temporo-parietal CVT with right side causing major mass effect which was decompressed. Lung imaging shows minimal apical lung ground glass opacities. This patient still remains to be in altered sensorium even after 20 days of in hospital stay suggestive of severe cerebral form of COVID-19 whereas the lung hardly showed any cause of his deteriorated condition. Also his chest $\mathrm{x}$-rays kept improving. His eosinophil count too remains to be around 0\% suggesting a severe form of cerebral COVID-19 which failed to improve in spite of near-normal respiratory condition. 
Table 1. Investigations and management of all seven patients.

\begin{tabular}{|c|c|c|c|c|c|c|c|c|c|}
\hline & Age/gender & Diagnosis & RT-PCR & Management & $\begin{array}{c}\text { APTT/PT/INR } \\
\text { (Electromechanical } \\
\text { clotting assay }\end{array}$ & DLC & LFT & RFT & Other \\
\hline 1 & $22 / \mathrm{M}$ & $\begin{array}{l}\text { Left temporo-parietal } \\
\text { CVT }(\mathrm{L}>\mathrm{R})\end{array}$ & + & $\begin{array}{l}\text { Left TPO DC + } \\
\text { AD }\end{array}$ & $38.1 / \underline{16.8} / \underline{1.33}$ & N-35, E-0, B-0 & $\begin{array}{l}\text { GRBS-308, } \\
\text { Bil-2.24 }\end{array}$ & $\mathrm{N}$ & $\begin{array}{l}\mathrm{LDH}-337, \\
\mathrm{CRP}>48\end{array}$ \\
\hline 2 & $38 / \mathrm{M}$ & $\begin{array}{l}\mathrm{b} / \mathrm{l} \text { fronto-temporal } \\
\text { CVT }(\mathrm{R}>\mathrm{L})\end{array}$ & + & $\begin{array}{l}\text { Right FTP DC } \\
+ \text { AD }\end{array}$ & $23.6 / 14.8 / 1.13$ & $\begin{array}{l}\text { N-74, E-0.9, } \\
\text { B-0.6 }\end{array}$ & $\begin{array}{l}\text { GRBS-232, } \\
\text { Rest-N }\end{array}$ & $\mathrm{N}$ & - \\
\hline 3 & $34 / \mathrm{M}$ & $\begin{array}{l}\mathrm{b} / \mathrm{l} \text { fronto-parietal } \\
\text { CVT }(\mathrm{R}>\mathrm{L})\end{array}$ & + & $\begin{array}{l}\text { Right FTP DC } \\
+\mathrm{AD}\end{array}$ & $29.2 / \underline{17.8} / \underline{1.43}$ & N-85, E- 0, B- 0 & $\begin{array}{l}\text { GRBS-108, } \\
\text { Rest-N }\end{array}$ & $\mathrm{N}$ & ESR-78 \\
\hline 4 & $30 / \mathrm{M}$ & $\begin{array}{l}\mathrm{b} / \mathrm{l} \text { parietal CVT }+ \\
\text { right fronto-parietal }\end{array}$ & + & $\begin{array}{l}\text { Right FTP DC } \\
+ \text { AD }\end{array}$ & $\underline{57.2} / 16.2 / \underline{1.27}$ & N-88, E-0, B-0 & $\begin{array}{l}\text { GRBS-120, } \\
\text { bil-3.4, } \\
\text { SGOT-169 }\end{array}$ & $\mathrm{N}$ & - \\
\hline 5 & $52 / \mathrm{F}$ & Left cerebellar CVT & + & $\begin{array}{l}\text { External } \\
\text { ventricular } \\
\text { drainage }\end{array}$ & 25.9/12.9/0.95 & $\begin{array}{l}\text { N-88, E-0.1, } \\
\text { B- } 0.3\end{array}$ & GRBS-252 & $\mathrm{N}$ & - \\
\hline 6 & $35 / \mathrm{M}$ & $\begin{array}{l}\text { Deep seated CVT- } \\
\text { Basal ganglia/bleed }\end{array}$ & + & $\begin{array}{l}\text { Medically } \\
\text { managed }\end{array}$ & $\underline{47.5 / 18.1 / 1.46}$ & $\begin{array}{l}\text { N-92, E-0, } \\
\text { B- } 0.1\end{array}$ & $\begin{array}{l}\text { GRBS-103/ } \\
\text { SGOT-189 }\end{array}$ & $\mathrm{N}$ & $\begin{array}{l}\mathrm{LDH}-532, \\
\mathrm{CRP}>48\end{array}$ \\
\hline 7 & $22 / \mathrm{M}$ & $\begin{array}{c}\text { Right parieto-occipital } \\
\text { CVT }\end{array}$ & + & $\begin{array}{l}\text { Right TPO DC } \\
+\mathrm{AD}\end{array}$ & $33.1 / 16.6 / \underline{1.31}$ & $\begin{array}{l}\text { N-89, E- } 0.1, \\
\text { B-0 }\end{array}$ & $\begin{array}{l}\text { GRBS-130, } \\
\text { bil-1.75 }\end{array}$ & $\mathrm{N}$ & - \\
\hline
\end{tabular}

GRBS (random)-mg/dl, N-neutrophils (\%), E-eosinophils (\%), B-basophils (\%), APTT)-activated partial thromboplastin time (27 - $39 \mathrm{sec})$, PT-Prothrombin time (10.4 - $16.2 \mathrm{sec})$, INR-international normalised ratio < 1.0, LDH-serum lactate dehydrogenase (U/L) (135 - 225), CRP-C-reactive protein (Latex agglutination), ESR-Erythrocyte sedimentation rate, LFT-liver function tests, RFT-Renal function tests, CVT-cerebral/cortical venous thrombosis/l-bilateral, FTP-fronto-temporo-parietal, DC-decompressive, $\mathrm{AD}$-augmentative duroplasty, TPO-temporo-parieto-occipital, RT-PCR-reverse transcriptase polymerase chain reaction for COVID-19, bil-bilirubin, SGOT-Serum glutamic Oxaloacetic transaminase.

Table 2. Case data and presentation of all seven patients.

\begin{tabular}{|c|c|}
\hline & Clinical symptomatology \\
\hline Case $1-22 / \mathrm{M}$ & $\begin{array}{l}\text { Sudden onset right focal motor seizures followed by weakness since } 1 \\
\text { day. K/c/o ALL on treatment with } 2 \text { chemotherapeutic drugs- } \\
\text { vincristine and daunorubicin. Nil other comorbidities } \\
\text { Examination: drowsy, obeying, vitals stable, pupils-BERL, Right side } \\
\text { hemiparesis }\end{array}$ \\
\hline Case $2-38 / \mathrm{M}$ & $\begin{array}{l}\text { RTA-two wheeler rider skid and fall under influence of alcohol, } \\
\text { followed by } 2 \text { episodes of vomiting and altered sensorium since then. } \\
\text { Nil comorbidities } \\
\text { Examination: comatose, localising to pain, pupil - left } 5 \mathrm{~mm} \mathrm{NR} \text {, left } \\
\text { upper limb monoparesis }\end{array}$ \\
\hline Case 3 - 34/M & $\begin{array}{l}\text { Headache and vomiting since } 1 \text { day, altered sensorium since he came to } \\
\text { hospital. Nil known comorbidities. } \\
\text { Examination: comatose, localising to pain, pupil-BERL }\end{array}$ \\
\hline Case 4 - 30/M & $\begin{array}{l}\text { Headache/vomiting since } 2 \text { days, altered sensorium and focal motor } \\
\text { seizures since } 1 \text { day. Nil comorbidities } \\
\text { Examination: comatose, localising to pain, pupil-BERL }\end{array}$ \\
\hline
\end{tabular}




\section{Continued}

Headache and vomiting since 3 days, altered sensorium since 1 day. Nil

Case $5-52 / F \quad k n o w n$ comorbidities. Not on OC pills or hormone replacement therapy. Examination - Intubated, coma, pupils - b/l $4 \mathrm{~mm} \mathrm{NR}$, dolls eye reflex absent

Altered sensorium found lying on road by police. Nil comorbidities.

Case 6 - 35/M Examination: comatose, localising to pain, pupil—b/l NR, left side hemiparesis

Headache/vomiting since 2 days, altered sensorium and left side weakness since 1 day. Nil comorbidities

Case 7 - 22/M Examination-comatose, localising to pain, pupil-PERL, left side hemiparesis

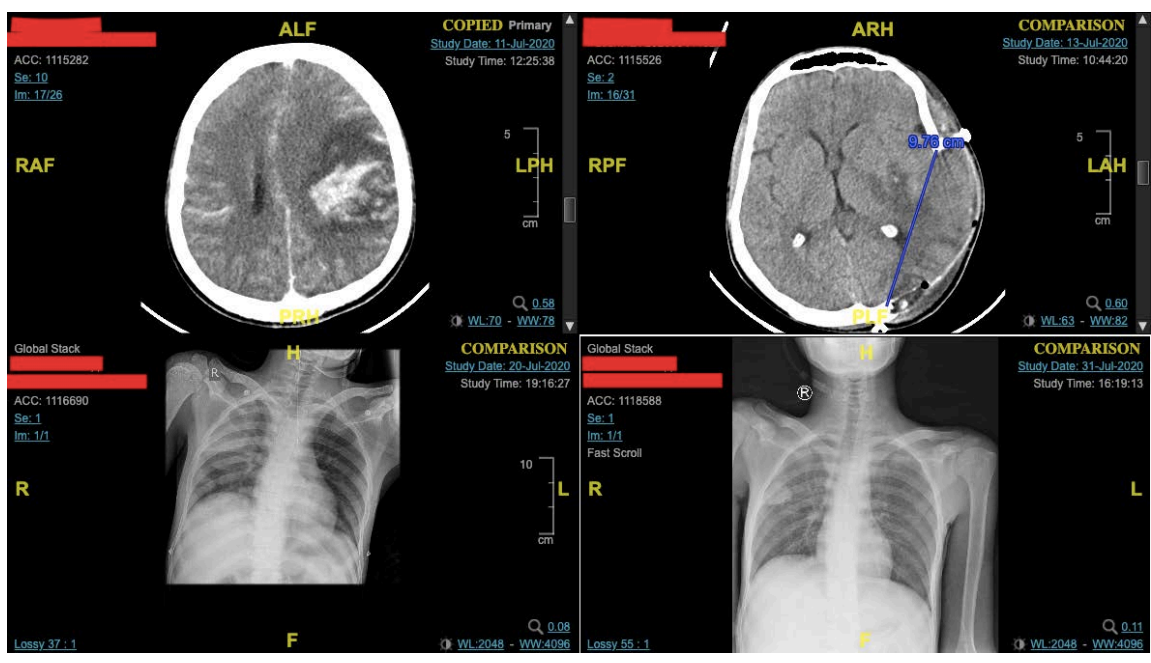

Figure 1. Represents the scan of case 1 of age 22 years. It shows CVT in the Left temporo-parietal region. Post-operative scan after 48 hours showed complete reversal of midline shift.

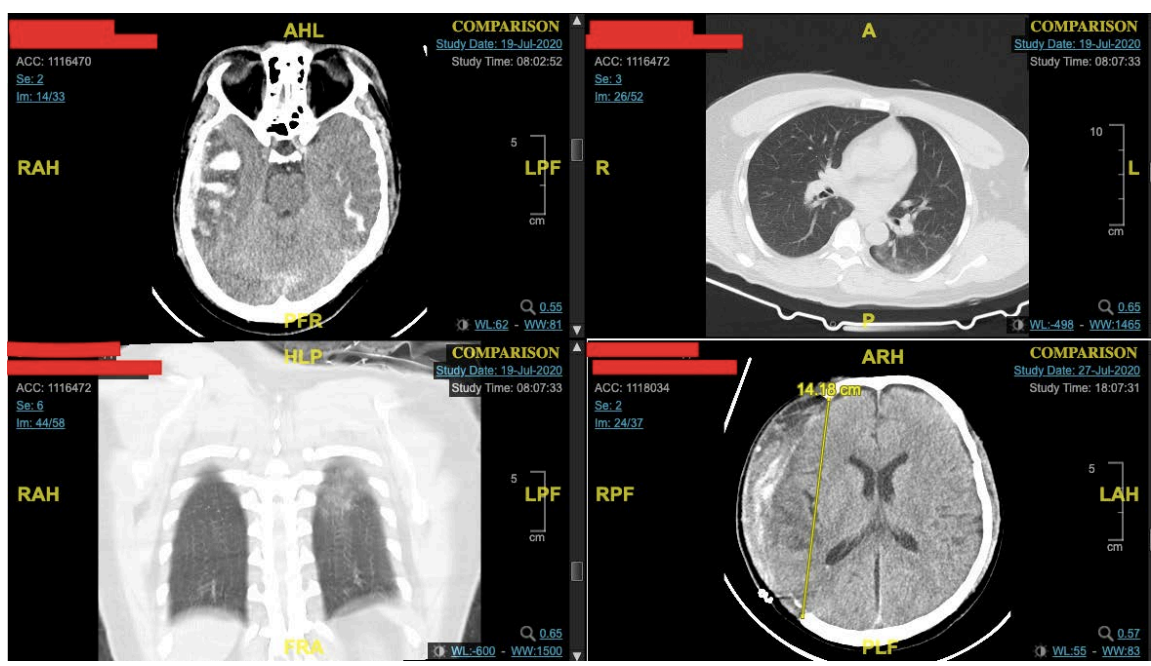

Figure 2. Shows a middle aged young male of age 38 years with bilateral temporo-parietal CVT with right side causing major mass effect which was decompressed. Lung imaging shows minimal apical lung ground glass opacities. 
$\underline{\text { Case } 3} \rightarrow$ (Figure 3 ) (Table 1) (Table 2) - It is a case (age 34/Male) of bilateral high fronto-parietal CVT with obliteration of mid-superior sagittal sinus with chest $\mathrm{x}$-ray showing mild ground glass opacities in the apical lung region. This patient remains to be in poor sensorium on ventilatory support with eosinophil counts being persistently low.

Case 4 (Table 1) (Table 2) $\rightarrow$ is a 30 year old male with bilateral high parietal CVT with decompression done for the right side. This patient had no chest pathology and even though his 20 day post-operative scan shows no midline shift he remains to be in altered sensorium on ventilatory support with progressive weaning.

Case $5 \rightarrow$ (Figure 4) (Table 1) (Table 2)-represents a 52 year old female with one of the rarest form of CVT $\rightarrow$ cerebellar and even so in COVID-19 positive status. She never had respiratory symptoms and chest $\mathrm{x}$ ray also did not reveal ground glass opacities.

Case $6 \rightarrow$ (Figure 5) (Table 1) (Table 2) - represents a 35 year old male with a right basal ganglia deep seated bleed with massive chest ground glass opacities in the apical and basal regions. In view of nil comorbidities and normal blood pressure and other parameters on presentation, vasculitis secondary to COVID-19 was favoured as possible cause.

Case 7 (Table 1) (Table 2) $\rightarrow$ Represents a 22 year old male patient with right parieto-occipital CVT. Chest $\mathrm{x}$-ray revealed apical ground glass opacities. He had no pulmonary symptoms. He improved in sensorium. At initial presentation his eosinophil count was also suggestive of severe form of COVID-19 infection. His chest $\mathrm{x}$-rays progressively improved.

\section{Discussion}

Human CoVs (HCoVs) have neurotropic and neuro-invasive potential [17]. Invasion may be direct via olfactory and gustatory tracts from nasal and oral mucosa

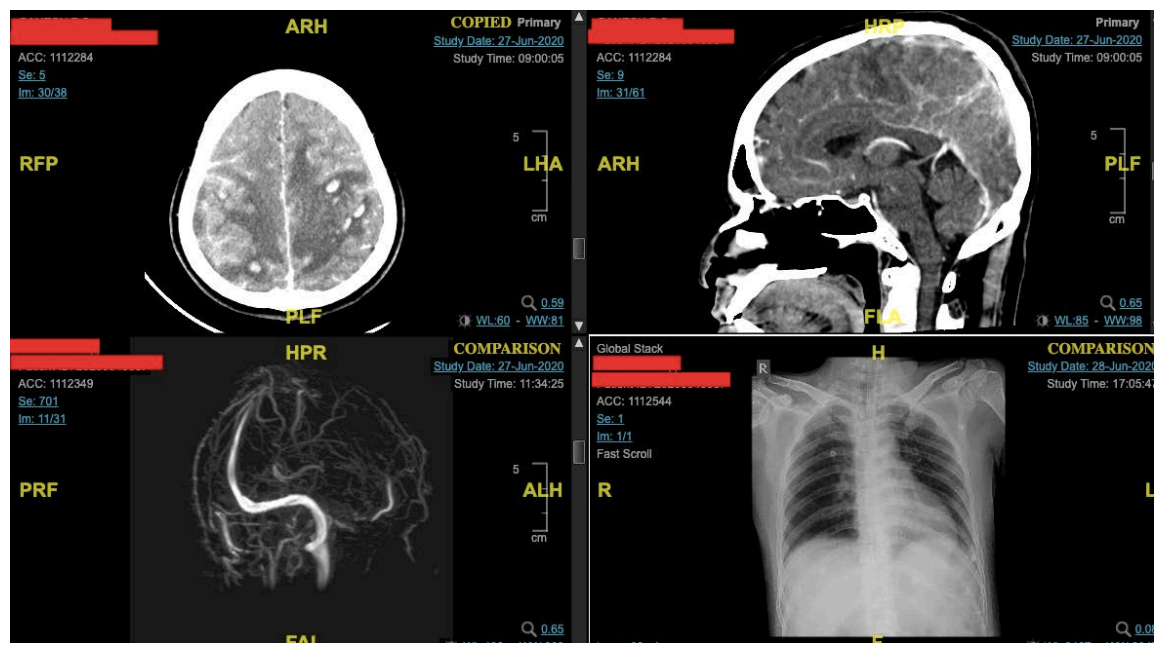

Figure 3. It is a case (age 34/Male) of bilateral high fronto-parietal CVT with obliteration of mid-superior sagittal sinus with chest $\mathrm{x}$-ray showing mild ground glass opacities in the apical lung region. 


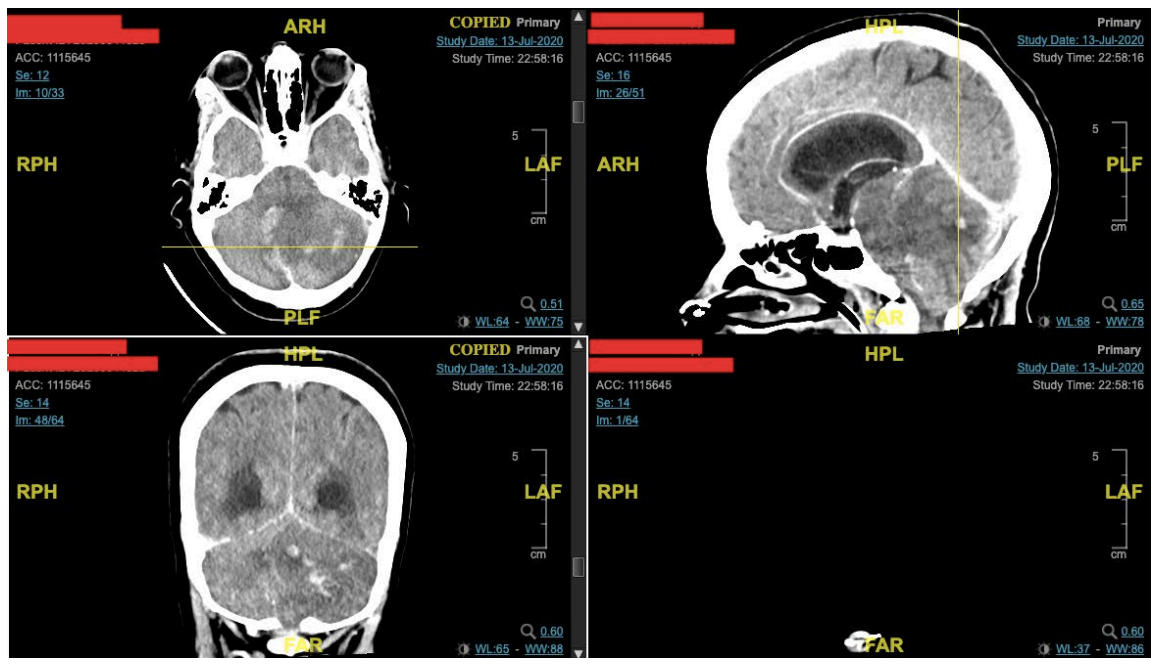

Figure 4. Represents a 52 year old female with one of the rarest form of CVT $\diamond$ cerebellar and even so in COVID-19 positive status. Chest $\mathrm{x}$ ray also did not reveal ground glass opacities.

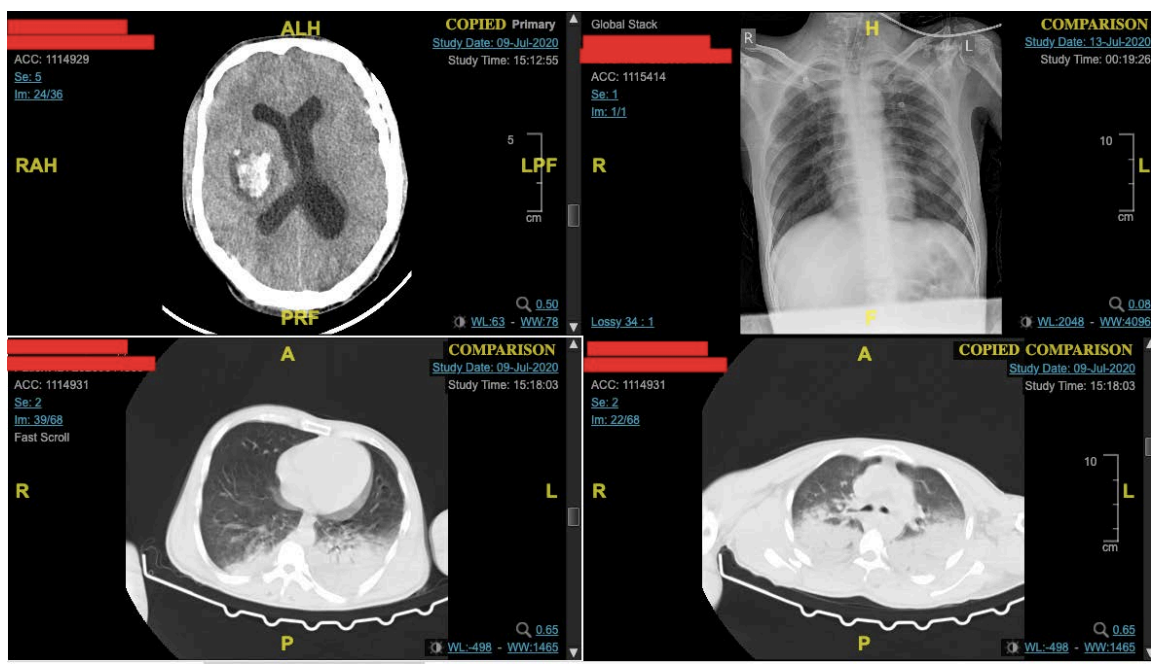

Figure 5. Represents a 35 year old male with a right basal ganglia deep seated bleed with massive chest ground glass opacities in the apical and basal regions.

Table 3. Represents epidemiology of CVT patients in 2019 and 2020 around same time of year in times of CORONA virus.

\begin{tabular}{|c|c|c|c|c|}
\hline \multirow{2}{*}{$\begin{array}{c}\text { Year } \\
\left(1^{\text {st }} \text { Mar to } 9^{\text {th }} \text { Aug) }\right.\end{array}$} & \multicolumn{2}{|c|}{ Total CVT cases } & \multirow{2}{*}{$\begin{array}{l}\text { Young males } \\
(10-40 \text { yrs. })\end{array}$} & \multirow{2}{*}{$\begin{array}{c}\text { Young females } \\
(10-40 \text { yrs.) }\end{array}$} \\
\hline & males & females & & \\
\hline 2019 & $11(20 \%)$ & $10(18 \%)$ & $8(38 \%)$ & $6(28 \%)$ \\
\hline 2020 & $13(29 \%)$ & $4(8 \%)$ & $12(70 \%)$ & $3(17 \%)$ \\
\hline
\end{tabular}

or via hematogenous dissemination as shown in many mice models [17]. Patho-physiological mechanisms may include a direct viral replication in neuronal and glial cells, cross-autoimmunity due to misdirected host immune response or 
a thrombotic state leading to local or widespread thrombosis secondary to SIRS and DIC similar to SARS-CoV [18]. It has been shown that increase in pro-inflammatory molecules leading to downstream disordered balance of pro vs anti-coagulation events cumulating into fibrin end-products increase the risk of coagulation in COVID-19 patients [18] [19] [20]. Hence the role of D-dimer in the management protocol and anticoagulation with heparin and its congeners are being studied extensively. Multiple case reports have shown both early and late pulmonary embolism and DIC in COVID-19 patients [19] [20]. Even the rates of DVT in such patients is comparatively high as compared to other patients on ventilatory support without COVID-19 being almost $17 \%$ in one study with incidence of pulmonary embolism being particularly high [21]. Multiple inflammatory markers like CRP, aPTT, ESR, D-dimer assay, LDH have been used to prognosticate and help in management of this deadly disease. The complement activation proteins, IL-6, IL-1 [22], TNF-alpha [23] have been shown to be particularly associated with increased risk of stroke in such patients. So also the role of renin-angiotensin system [24] in the pathogenesis of stroke and protective effect of RAS alternative pathway [25] [26] [27] are also been predicted.

The $1^{\text {st }}$ case (Figure 1 ) was a known case of ALL with covid positive status. The GRAALL [28], CAPELAL [29], PARKAA [30] studies have shown that the risk of venous thromboembolism in ALL patients during induction with 1-asparaginase (l-ASP) is anywhere between $1 \%-36 \%$ on average being $3 \%-4 \%$ which most commonly occur in children and young adults. Other factors responsible are central venous catheters, combination therapy with vincristine or corticosteroids. The levels of antithrombin are particularly low in such patients [28] [29]. In this patient, though his age was 22 years he was never started on -asparaginase (1-ASP). He was diagnosed just 1.5 months prior to presentation and was on vincristine and daunorubicin with corticosteroids. He was never on central venous catheters. Even though he was started on above drugs the incidence of cerebral CVT is very rare in absence of l-ASP. Also the picture of low eosinophil count may point towards COVID-19 virus as the cause of CVT though both the conditions may be contributing. Hence, we would like to consider COVID-19 as a potential cause for inducing thrombosis superimposed over already compromised immune system. The neutrophil was particularly low along with decreased anticoagulation profile. The above patient had no respiratory symptoms and his chest improved with continued care in ICU.

$5^{\text {th }}$ case (Figure 4 ) is a rare case of cerebellar CVT in an old lady with COVID-19 status. This patient had a very poor prognosis and presented with acute hydrocephalus with GCS of 3 who underwent external ventricular drainage. This patient had only mild fever with sore throat which was managed medically by a physician since 3 - 4 days. She belonged to red zone which meant high load of positive covid-19 patients. Such a case with cerebellar CVT in patient with covid-19 has never been reported as per our knowledge. The above patient had no comorbidities and was from good socioeconomic status. Nothing apart from the 
distorted coagulation profile due to COVID-19 could explain her acute symptomatology. Further investigations could not be carried out in view of her early death.

$6^{\text {th }}$ case (Figure 5) is a case of deep seated basal ganglia bleed which is reported less in COVID-19 patients with no known comorbidities. Relative young age (35 years) with altered sensorium at presentation in absence of mass effect favoured vasculitis as the possible cause of bleed secondary to COVID-19 induced SIRS/DIC. This patient was not a known hypertensive and at presentation had a systolic blood pressure of $130 \mathrm{~mm} \mathrm{hg}$ and diastolic of $80 \mathrm{~mm}$ hg. Further investigation could not be carried out due to full occupancy of ventilatory beds in our institute and patient was discharged to another tertiary care facility.

Out of the 98 COVID-19 positive cases presenting to our institute with neurological symptoms from March $1^{\text {st }}$ to $9^{\text {th }}$ august 2020, 8 COVID-19 positive CVT cases were operated with decompressive craniectomy. Although the total CVT cases were 45 . Out of which 12 (70\%) were young males from 10 - 40 years of age (Table 3). Around same time in 2019 the amount of operated young males for CVT were 8 (38\%) which suggest a sharp rise to almost double in the incidence of young males. Whether Covid-19 is a direct cause or a superimposition on a compromised situation of economic and social constraints of developing country like India is intriguing. It would be of great interest to know if the developed countries or other countries with poor economic condition are having the same trend. If so, it would be easier to point a direct correlation of Covid-19 affection in young males. But why it has to affect more of young males, remains far from understood and requires further thorough studies. Also among the 7 cases presented 6 of them are young males. 5 did not have any prior known comorbidity. Other patients had near normal RFT with disturbance mainly in coagulation profile, Liver functions and peripheral eosinophil and basophil counts with increase in percentage of neutrophils. Chronic alcoholism was not known in these patients though 3 were occasional drinkers. This trend shows an increase in the incidence of CVT in young males. This neurotropism for young healthy males is far from understood. We know CVT is more common a disease of young reproductive females or males with history of chronic alcoholism. The ratio in this age group is almost 3:1 in favour of young females with $80 \%$ being less than 50 years of age [31] [32]. The picture we see here is exactly opposite. Not only the young females are being less operated, but also the young males are presenting more and more of them requiring surgical treatment. Our study does face a drawback of having only a surgical case series which may underestimate the number of young females who were not operated and managed medically. But the sharp rise in number of operable young males with no comorbidities is quite alarming.

Among the cases presented here; all except one had a disturbed coagulation profile. Also the eosinophil and basophil count in peripheral blood were extremely low in all the patients. Four out of above seven patients have altered liver 
functions with increased bilirubin and SGOT suggesting a pan-liver involvement secondary to COVID-19 as they were not chronic alcoholics. This may be secondary to SIRS or DIC. All the patients are still under ICU care with clear chest but still in altered sensorium requiring continued ventilatory support all having completed at least 20 days following surgery.

Eosinophil count is known to predict severity in COVID-19 cases [33] [34]. But most of these severe cases had pulmonary manifestations. It has been shown that with gradual improvement in chest imaging there is improvement in eosinophil count and the latter is correlated with severity if less [33] [34] [35]. None of the above patients had cerebral manifestations. So we are yet not sure how do eosinophil and basophil counts behave in primary cerebral COVID-19 cases. Our data suggests that low eosinophil count points towards severity in cerebral and pulmonary COVID-19 and its non-improvement in these primary cases may suggest continued poor prognosis. Whether low eosinophil counts portend to poor prognosis or severe COVID-19 leads to low eosinophil count is unclear and difficult to tell. Also our sample size is too small to achieve any significance in comparison with general population. A larger sample size in this regard would definitely help the cause. Nonetheless, multiple studies have been published signifying the protective importance of normal to high eosinophil count in COVID-19 patients [33] [34] [35]. Few studies even point out protectivity of high eosinophil counts in asthmatic patients to severe respiratory COVID-19 infection [36]. This may suggest that though their chest physiology did improve, their cerebral or VTE or DIC proneness did not improve. The non-improvement in our cases could also suggest that low eosinophil count may be persisting due to persistent covid virus load in above patients as their RT-PCR continued to be positive. Although few had LDH levels which were quite high initially, it did show a drop in levels with improvement of GCS which may be an important prognostic factor in the future as suggested by few studies [37] [38].

\section{Lessons Learnt}

This proneness for neurotropism of COVID-19 virus in relatively asymptomatic young males is far from understood and requires further large prospective studies. Also the role of peripheral blood picture and LDH needs to be better elucidated along with other risk factors for better prognostication specially in CVT cases as cerebral COVID-19 cases seem to behave differently. Cerebral COVID-19 is more severe with very meagre data on prognostic factors as most of data is being extrapolated from pulmonary COVID-19 cases. We hypothesize that the neurotropic virus may have a slightly different genomic expression with variable site of attachment and hence variable immune response which may shield it from body's immune system for prolonged period of time or provide an immune privilege. Above hypothesis could only be tested with time as more and more data on CVT in COVID-19 keeps accumulating. Also whether vaccination would affect the overall blood picture and presentation in young patients remains to be 
seen and definitely a subject of intrigue.

\section{Conflicts of Interest}

The authors declare no conflicts of interest.

\section{References}

[1] He, F., Deng, Y. and Li, W. (2020) Coronavirus Disease 2019: What We Know? Journal of Medical Virology, 92, 719-725. https://doi.org/10.1002/jmv.25766

[2] Wang, Y., Wang, Y., Chen, Y. and Qin, Q. (2020) Unique Epidemiological and Clinical Features of the Emerging 2019 Novel Coronavirus Pneumonia (COVID-19) Implicate Special Control Measures. Journal of Medical Virology, 92, 568-576. https://doi.org/10.1002/jmv.25748

[3] Wrapp, D., et al. (2020) Cryo-EM Structure of the 2019-nCoV Spike in the Prefusion Conformation. Science, 367, 1260-1263. https://doi.org/10.1126/science.abb2507

[4] Zhou, P., et al. (2020) A Pneumonia Outbreak Associated with a New Coronavirus of Probable Bat Origin. Nature, 579, 270-273.

https://www.nature.com/articles/s41586-020-2012-7 https://doi.org/10.1038/s41586-020-2012-7

[5] Letko, M., Marzi, A. and Munster, V. (2020) Functional Assessment of Cell Entry and Receptor Usage for SARS-CoV-2 and Other Lineage B Betacoronaviruses. Nature Microbiology, 5, Article No. 4. https://doi.org/10.1038/s41564-020-0688-y

[6] Hamming, I., et al. (2004) Tissue Distribution of ACE2 Protein, the Functional Receptor for SARS Coronavirus. A First Step in Understanding SARS Pathogenesis. The Journal of Pathology, 203, 631-637. https://doi.org/10.1002/path.1570

[7] Bohmwald, K., Gálvez, N.M.S., Ríos, M. and Kalergis, A.M. (2018) Neurologic Alterations Due to Respiratory Virus Infections. Frontiers in Cellular Neuroscience, 12, Article No. 386. https://doi.org/10.3389/fncel.2018.00386 https://www.frontiersin.org/articles/10.3389/fncel.2018.00386/full

[8] Bhatia, R. and Srivastava, M.V.P. (2020) COVID-19 and Stroke: Incidental, Triggered or Causative. Annals of Indian Academy of Neurology, 23, 318-324.

[9] Divani, A.A., et al. (2020) Coronavirus Disease 2019 and Stroke: Clinical Manifestations and Pathophysiological Insights. Journal of Stroke and Cerebrovascular Diseases, 29, Article ID: 104941.

https://doi.org/10.1016/i.jstrokecerebrovasdis.2020.104941

[10] Cavalcanti, D.D., et al. (2020) Cerebral Venous Thrombosis Associated with COVID19. American Journal of Neuroradiology, 41, 1370-1376. https://doi.org/10.3174/ajnr.A6644

[11] Chougar, L., Mathon, B., Weiss, N., Degos, V. and Shor, N. (2020) Atypical Deep Cerebral Vein Thrombosis with Hemorrhagic Venous Infarction in a Patient Positive for COVID-19. American Journal of Neuroradiology, 41, 1377-1379. https://doi.org/10.3174/ajnr.A6642

[12] Garaci, F., Di Giuliano, F., Picchi, E., Da Ros, V. and Floris, R. (2020) Venous Cerebral Thrombosis in COVID-19 Patient. Journal of the Neurological Sciences, 414, Article ID: 116871. https://doi.org/10.1016/j.jns.2020.116871

[13] Helms, J., et al. (2020) Neurologic Features in Severe SARS-CoV-2 Infection. New England Journal of Medicine, 382, 2268-2270. https://doi.org/10.1056/NEJMc2008597 
[14] Robinson, C.P. and Busl, K.M. (2020) Neurologic Manifestations of Severe Respiratory Viral Contagions. Critical Care Explorations, 2, e0107. https://doi.org/10.1097/CCE.0000000000000107

[15] Klok, F.A., et al. (2020) Incidence of Thrombotic Complications in Critically Ill ICU Patients with COVID-19. Thrombosis Research, 191, 145-147. https://doi.org/10.1016/j.thromres.2020.04.013

[16] Hughes, C., Nichols, T., Pike, M., Subbe, C. and Elghenzai, S. (2020) Cerebral Venous Sinus Thrombosis as a Presentation of COVID-19. European Journal of Case Reports in Internal Medicine, 7, Article ID: 001691.

[17] Zhou, Z., Kang, H., Li, S. and Zhao, X. (2020) Understanding the Neurotropic Characteristics of SARS-CoV-2: From Neurological Manifestations of COVID-19 to Potential Neurotropic Mechanisms. Journal of Neurology, 267, 2179-2184. https://doi.org/10.1007/s00415-020-09929-7

[18] Tang, N., Li, D., Wang, X. and Sun, Z. (2020) Abnormal Coagulation Parameters Are Associated with Poor Prognosis in Patients with Novel Coronavirus Pneumonia. Journal of Thrombosis and Haemostasis, 18, 844-847. https://doi.org/10.1111/jth.14768

[19] Ullah, W., Saeed, R., Sarwar, U., Patel, R. and Fischman, D.L. (2020) COVID-19 Complicated by Acute Pulmonary Embolism and Right-Sided Heart Failure. JACC: Case Reports, 2, 1379-1382. https://doi.org/10.1016/j.jaccas.2020.04.008

[20] Xie, Y., Wang, X., Yang, P. and Zhang, S. (2020) COVID-19 Complicated by Acute Pulmonary Embolism. Radiology: Cardiothoracic Imaging, 2, e200067. https://doi.org/10.1148/ryct.2020200067

[21] UPI.com (2020) High Number of Patients with Severe COVID-19 Develop Deep Vein Thrombosis.

https://www.upi.com/Health News/2020/05/29/High-number-of-patients-with-sev ere-COVID-19-develop-deep-vein-thrombosis/4171590761951

[22] Conti, P., et al. (2020) Induction of Pro-Inflammatory Cytokines (IL-1 and IL-6) and Lung Inflammation by Coronavirus-19 (CoV-19 or SARS-CoV-2): Anti-Inflammatory Strategies. Journal of Biological Regulators and Homeostatic Agents, 34, 327-331.

https://www.biolifesas.org/biolife/2020/03/15/induction-of-pro-inflammatory-cytok in-

es-il-1-and-il-6-and-lung-inflammation-by-covid-19-anti-inflammatory-strategies

[23] Huang, C.L., et al. (2020) Clinical Features of Patients Infected with 2019 Novel Coronavirus in Wuhan, China. The Lancet, 395, 497-506.

https://www.thelancet.com/journals/lancet/article/PIIS0140-6736(20)30183-5/fullte $\underline{\mathrm{xt}}$

https://doi.org/10.1016/S0140-6736(20)30183-5

[24] Li, W., et al. (2003) Angiotensin-Converting Enzyme 2 Is a Functional Receptor for the SARS Coronavirus. Nature, 426, Article No. 6965. https://doi.org/10.1038/nature02145

[25] Bennion, D.M., Haltigan, E., Regenhardt, R.W., Steckelings, U.M. and Sumners, C. (2015) Neuroprotective Mechanisms of the ACE2-Angiotensin-(1-7)-Mas Axis in Stroke. Current Hypertension Reports, 17, 3. https://doi.org/10.1007/s11906-014-0512-2

[26] Hofmann, H., et al. (2004) Susceptibility to SARS Coronavirus S Protein-Driven Infection Correlates with Expression of Angiotensin Converting Enzyme 2 and Infection Can Be Blocked by Soluble Receptor. Biochemical and Biophysical Research Communications, 319, 1216-1221. https://doi.org/10.1016/j.bbrc.2004.05.114 
[27] Haschke, M., et al. (2013) Pharmacokinetics and Pharmacodynamics of Recombinant Human Angiotensin-Converting Enzyme 2 in Healthy Human Subjects. Clinical Pharmacokinetics, 52, 783-792. https://doi.org/10.1007/s40262-013-0072-7

[28] Couturier, M.-A., et al. (2015) Cerebral Venous Thrombosis in Adult Patients with Acute Lymphoblastic Leukemia or Lymphoblastic Lymphoma during Induction Chemotherapy with 1-Asparaginase: The GRAALL Experience. American Journal of Hematology, 90, 986-991. https://doi.org/10.1002/ajh.24130

[29] Hunault-Berger, M., et al. (2008) Changes in Antithrombin and Fibrinogen Levels during Induction Chemotherapy with L-asparaginase in Adult Patients with Acute Lymphoblastic Leukemia or Lymphoblastic Lymphoma. Use of Supportive Coagulation Therapy and Clinical Outcome: The CAPELAL Study. Haematologica, 93, 1488-1494. https://doi.org/10.3324/haematol.12948

[30] Mitchell, L.G., et al. (2003) A Prospective Cohort Study Determining the Prevalence of Thrombotic Events in Children with Acute Lymphoblastic Leukemia and a Central Venous Line Who Are Treated with L-asparaginase: Results of the Prophylactic Antithrombin Replacement in Kids with Acute Lymphoblastic Leukemia Treated with Asparaginase (PARKAA) Study. Cancer, 97, 508-516.

https://doi.org/10.1002/cncr.11042

[31] Silvis, S.M., de Sousa, D.A., Ferro, J.M. and Coutinho, J.M. (2017) Cerebral Venous Thrombosis. Nature Reviews Neurology, 13, Article No. 9.

https://doi.org/10.1038/nrneurol.2017.104

[32] Field, T.S. and Hill, M.D. (2019) Cerebral Venous Thrombosis. Stroke, 50, 1598-1604. https://doi.org/10.1161/STROKEAHA.119.025334

[33] Xie, G., Ding, F., Han, L., Yin, D., Lu, H. and Zhang, M. (2021) The Role of Peripheral Blood Eosinophil Counts in COVID-19 Patients. Allergy, 76, 471-482. https://doi.org/10.1111/all.14465

[34] Lindsley, A.W., et al. (2020) Eosinophil Responses during COVID-19 Infections and Coronavirus Vaccination. The Journal of Allergy and Clinical Immunology, 146, 1-7. https://doi.org/10.1016/j.jaci.2020.04.021 https://www.researchgate.net/publication/340942003 Eosinophil Responses Durin g COVID-19 Infections and Coronavirus Vaccination

[35] Sun, D., et al. (2020) The Underlying Changes and Predicting Role of Peripheral Blood Inflammatory Cells in Severe COVID-19 Patients: A Sentinel? Clinica Chimica Acta, 508, 122-129. https://doi.org/10.1016/j.jaci.2020.04.021

[36] Rodriguez, C. and Veciana, C. (2020) Asthma and Covid-19: The Eosinophilic Link. Qeios, Apr. https://doi.org/10.32388/5IY4IF

[37] Henry, B.M., et al. (2020) Lactate Dehydrogenase Levels Predict Coronavirus Disease 2019 (COVID-19) Severity and Mortality: A Pooled Analysis. The American Journal of Emergency Medicine, 38, 1722.

https://doi.org/10.1016/j.ajem.2020.05.073

[38] Wu, M., et al. (2020) Clinical Evaluation of Potential Usefulness of Serum Lactate Dehydrogenase (LDH) in 2019 Novel Coronavirus (COVID-19) Pneumonia. Res piratory Research, 21, Article No. 171. https://doi.org/10.1186/s12931-020-01427-8 